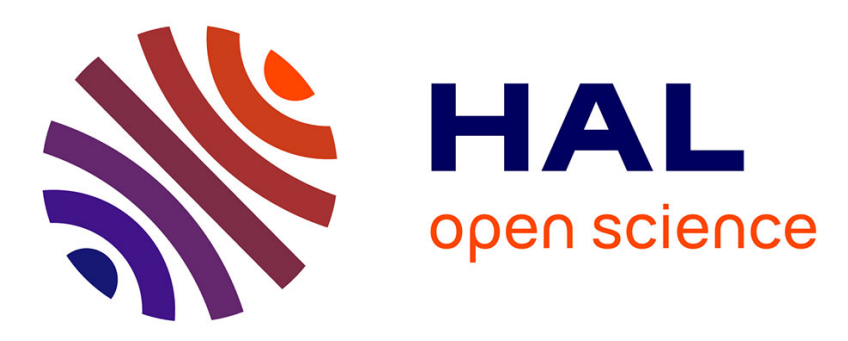

\title{
Introducing angularly periodic disturbances in dynamic models of rotating systems under non-stationary conditions
}

\author{
A. Bourdon, Hugo Andre, Didier Rémond
}

\section{- To cite this version:}

A. Bourdon, Hugo Andre, Didier Rémond. Introducing angularly periodic disturbances in dynamic models of rotating systems under non-stationary conditions. Mechanical Systems and Signal Processing, 2014, Special Issue on Instantaneous Angular Speed (IAS) Processing and Angular Applications, 44 (1-2), pp.60-71. 10.1016/j.ymssp.2013.09.004 . hal-00916259

\section{HAL Id: hal-00916259 \\ https://hal.science/hal-00916259}

Submitted on 3 Jun 2019

HAL is a multi-disciplinary open access archive for the deposit and dissemination of scientific research documents, whether they are published or not. The documents may come from teaching and research institutions in France or abroad, or from public or private research centers.
L'archive ouverte pluridisciplinaire HAL, est destinée au dépôt et à la diffusion de documents scientifiques de niveau recherche, publiés ou non, émanant des établissements d'enseignement et de recherche français ou étrangers, des laboratoires publics ou privés.

$$
\text { Copyright }
$$




\title{
Introduction of Angularly Periodic Disturbances in Dynamic Models of Rotating Systems under Non-Stationary Conditions.
}

\author{
Adeline Bourdon ${ }^{1}$, Hugo André2, Didier Rémond \\ ${ }^{1}$ Université de Lyon, CNRS, UMR5259 \\ INSA-Lyon, LaMCoS F-69621, France \\ adeline.bourdon@insa-lyon.fr \\ didier.remond@insa-lyon.fr \\ ${ }^{2}$ Maïa Eolis, Tour de LILLE, \\ Bd de Turin 59777 LILLE, France \\ handre@maiaeolis.fr
}

\begin{abstract}
Existence of a mechanical defect in a rotating system can be interpreted as the presence of a periodic angular perturbation. Understanding the interactions between the defect and its consequences on measurable quantities representative of dynamic behavior (acceleration, speed ...) necessarily involves the implementation of numerical models. The aim of this paper is to present a model suitable for the introduction of this kind of disturbance in the case of systems operating under non-stationary speed conditions. This model corresponds to a numerical extension of approaches increasingly used to analyze experimental signals.

Based on the model built, investigation of the influence of disturbance parameters on the dynamic responses of the rotating system can be performed. This model also allows comparisons of new assumptions on the origin of this perturbation. The general framework of bearing faults will be the support used to illustrate this new approach.
\end{abstract}

\section{Highlights:}

This paper focuses on the use of angular model to describe faulty bearing behaviour.

Instantaneous Angular Speed is shown to be a key signal for fault detection.

This leads to consider other manifestation of defect in bearing behaviour and to introduce a torque applied on rotating shaft.

Model simulations offers the possibility to estimate this torque level by comparing induced speed variation on expérimental measurements.

\section{Keywords:}

Mechanical Fault - Dynamic Model - Non stationary Conditions - Angular Model - Rotating Machines Instantaneous Angular Speed.

\section{Introduction}

\subsection{General Background}

This work is part of the broader framework of monitoring and maintenance of rotating machinery. The aim of this paper is to propose a dynamic modeling of a rotating shaft under non-stationary operating conditions, and subjected to disturbances representative of presence of mechanical defects on rotating components (gears, bearings ...). Based on these models, the medium-term objective is to build a better understanding and a better analysis of experimental results obtained through measurements.

This work was initiated in parallel with experimental ones which, in the case of rotating systems under non-stationary operations, have demonstrated the major interest of angular sampling and the relevance of analysis the Instantaneous Angular Speed (I.A.S.) signal. Angular sampling can be achieved directly or after time sampling with different interpolation procedures [7]. All these angular approaches are now very well-known [8] and used for different kind of 
signals, historically from accelerometer signals. Several authors have demonstrated the effectiveness of I.A.S. signal [1] and used it in various applications [2, 4, 5]. I.A.S. seems to be very useful and sensitive in monitoring [6] and diagnosis of different faults in rotating machines with discrete geometry in variable operating conditions $[3,5]$.

Nevertheless, these experimental approaches are not sufficient to understand the origins of these phenomena and their interactions [7]. They must be coupled with the realization of numerical models where the operating conditions and the geometry of the device can be controlled and changed. Building such models requires introduction of perturbations representative of the presence of defects in the mechanism. In this context, extension of the angular approach implemented experimentally appears naturally in numerical models [10]. Since the approach proposed in this paper is very new and out of classical modeling, it has been difficult to find similar modeling methods in other scientific fields and the literature on the subject appears very poor to the knowledge of the authors.

\subsection{General model}

We consider later the case of a rotating flexible shaft, modeled by a discrete representation with $\mathrm{n}$ degrees of freedom (DOF), which can be expressed by the following matrix differential equation:

$$
[\mathrm{M}]_{\mathrm{nxn}} \cdot\{\ddot{\mathrm{X}}\}_{\mathrm{n}}+[\mathrm{C}]_{\mathrm{n} \times n} \cdot\{\dot{\mathrm{X}}\}_{\mathrm{n}}+[\mathrm{K}]_{\mathrm{n} \times n} \cdot\{\mathrm{X}\}_{\mathrm{n}}=\left\{\mathrm{F}_{\mathrm{ext}}\right\}_{\mathrm{n}}
$$

where $\{\mathrm{X}\}$ is the vector of generalized displacements, $[\mathrm{M}],[\mathrm{C}],[\mathrm{K}]$ are the matrices of mass, damping, stiffness and $\left\{\mathrm{F}_{\mathrm{ext}}\right\}$ the vector of external forces (driving and resistant forces). The system defined by the equation (1) has a rigid mode corresponding to the free rotation of the shaft.

This system of $n$ differential equations of order 2 can be rewritten as a system of $2 n$ equations of order 1 by setting:

$$
\{\mathrm{Q}\}_{2 \mathrm{n}}=\left\{\begin{array}{l}
\{\mathrm{X}\}_{\mathrm{n}} \\
\{\dot{\mathrm{X}}\}_{\mathrm{n}}
\end{array}\right\}
$$

Then, system (1) becomes:

$$
\left[\begin{array}{cc}
{\left[\mathrm{I}_{\mathrm{d}}\right]} & {[0]} \\
{[0]} & {[\mathrm{M}]}
\end{array}\right] \cdot\left\{\begin{array}{l}
\{\dot{\mathrm{X}}\} \\
\{\ddot{\mathrm{X}}\}
\end{array}\right\}=\left\{\begin{array}{c}
\{0\} \\
\left\{\mathrm{F}_{\text {ext }}\right\}
\end{array}\right\}-\left[\begin{array}{cc}
{[0]} & -\left[\mathrm{I}_{\mathrm{d}}\right] \\
{[\mathrm{K}]} & {[\mathrm{C}]}
\end{array}\right] \cdot\left\{\begin{array}{c}
\{\mathrm{X}\} \\
\{\dot{\mathrm{X}}\}
\end{array}\right\}
$$

where $\left[I_{d}\right]$ is the identity matrix of dimension $n$. Whether derivative of state vector can be expressed as

$$
\{\dot{\mathrm{Q}}\}=\left[\begin{array}{cc}
{\left[\mathrm{I}_{\mathrm{d}}\right]} & {[0]} \\
{[0]} & {[\mathrm{M}]^{-1}}
\end{array}\right] \cdot\left(\left\{\begin{array}{c}
\{0\} \\
\left\{\mathrm{F}_{\text {ext }}\right\}
\end{array}\right\}-\left[\begin{array}{cc}
{[0]} & -\left[\mathrm{I}_{\mathrm{d}}\right] \\
{[\mathrm{K}]} & {[\mathrm{C}]}
\end{array}\right] \cdot\{\mathrm{Q}\}\right)
$$

then equation (1) can be written as:

$$
\{\dot{\mathrm{Q}}\}=\left[\begin{array}{cc}
{\left[\mathrm{I}_{\mathrm{d}}\right]} & {[0]} \\
{[0]} & {[\mathrm{M}]^{-1}}
\end{array}\right] \cdot\left[\begin{array}{cc}
{[0]} & {\left[\mathrm{I}_{\mathrm{d}}\right]} \\
-[\mathrm{K}] & -[\mathrm{C}]
\end{array}\right] \cdot\{\mathrm{Q}\}+\left[\begin{array}{cc}
{\left[\mathrm{I}_{\mathrm{d}}\right]} & {[0]} \\
{[0]} & {[\mathrm{M}]^{-1}}
\end{array}\right]\left\{\begin{array}{c}
\{0\} \\
\left\{\mathrm{F}_{\mathrm{ext}}\right\}
\end{array}\right\}
$$

\section{Parametric modeling of the disturbance and related issues}

\subsection{Definition of the disturbance}

The disturbance considered in this document must be representative of the presence of a fault on a mechanical moving element of a rotating system, so it will be angularly periodic. Let $\theta$ be the angular degree of freedom associated with the mechanical organ having the defect. From a mechanical point of view, this disturbance can be equivalent to a variation of the external forces $\left\{\Delta \mathrm{F}_{\mathrm{p}}(\theta)\right\}$ and/or for the defective organ to a variation of its stiffness $\left[\Delta \mathrm{K}_{\mathrm{p}}(\theta)\right]$ and/or to a variation of its damping $\left[\Delta \mathrm{C}_{\mathrm{p}}(\theta)\right]$. Current knowledge does not allow choosing for one of these assumptions. The most suitable modeling will be defined in future works by using comparisons between experimental and simulation results. In the general case where the presence of defect modifies the external forces, the damping, the rigidity, dynamic equation (1) governing the behavior of the system becomes: 


$$
[\mathrm{M}] \cdot\{\ddot{\mathrm{X}}\}+\left[[\mathrm{C}]+\Delta \mathrm{P}_{\mathrm{c}}(\theta) \cdot\left[\mathrm{G}_{\mathrm{c}}\right]\right] \cdot\{\dot{\mathrm{X}}\}+\left[[\mathrm{K}]+\Delta \mathrm{P}_{\mathrm{k}}(\theta) \cdot\left[\mathrm{G}_{\mathrm{k}}\right]\right] \cdot\{\mathrm{X}\}=\left\{\mathrm{F}_{\mathrm{ext}}\right\}+\Delta \mathrm{P}_{\mathrm{F}}(\theta) \cdot\left\{\mathrm{G}_{\mathrm{F}}\right\}
$$

or, in the state space form:

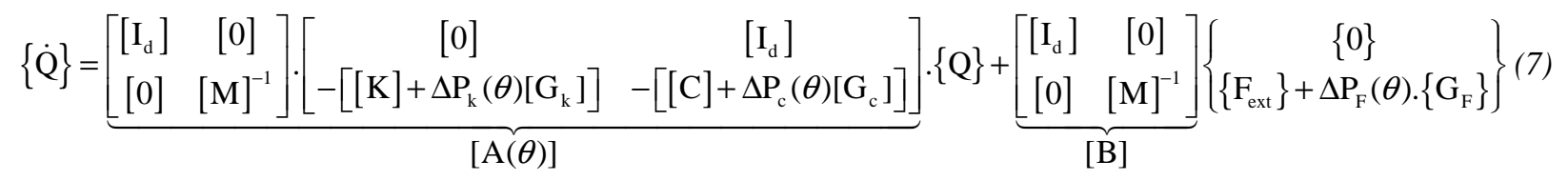

where $\Delta \mathrm{P}_{\mathrm{c}}(\theta), \Delta \mathrm{P}_{\mathrm{k}}(\theta), \Delta \mathrm{P}_{\mathrm{F}}(\theta)$ are scalar values defining the disturbance and $\left\{\mathrm{G}_{\mathrm{f}}\right\},\left[\mathrm{G}_{\mathrm{c}}\right],\left[\mathrm{G}_{\mathrm{k}}\right]$ respectively a vector and geometrical dimensionless matrices connecting the previous scalars defining the perturbation to the model d.o.f.

$\Delta \mathrm{P}_{\mathrm{j}}(\theta)(\mathrm{j}=\mathrm{c}, \mathrm{k}, \mathrm{F})$ is characterized by its angular period $\theta_{\mathrm{o}}$ and its angular length $\mathrm{L}_{\theta}$. The latter is assumed to be small and representative of a localized perturbation. To a first approximation $\Delta \mathrm{P}_{\mathrm{j}}(\theta)$ is modeled as a half sine of amplitude $\mathrm{A}_{\mathrm{p}}$, but other shapes are evidently possible. Nevertheless, a modeling using impulse does not seem relevant because it is not representative of physical reality and also leads to numerical instabilities. Figure 1.a is used to display the disturbance modeling parameters.

a) Parametric definition

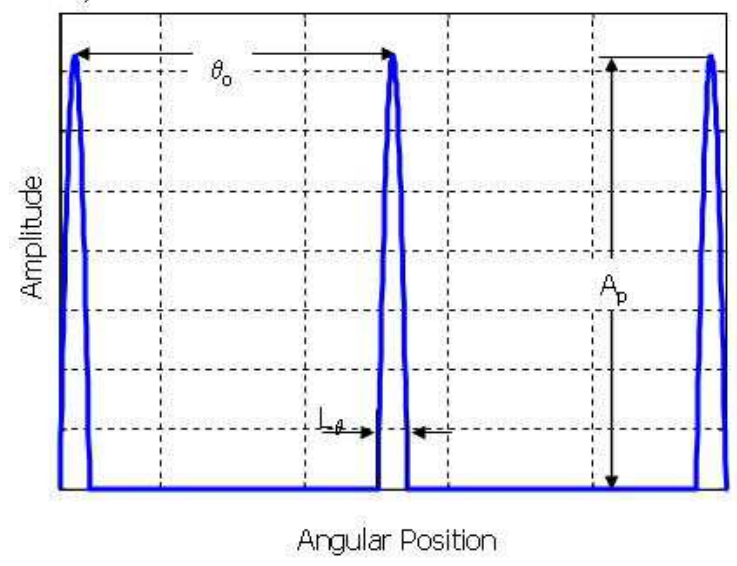

b) Partition

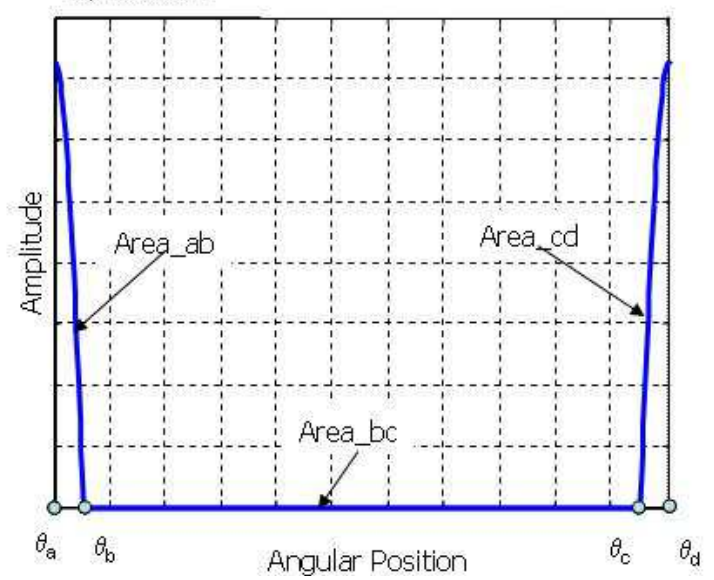

Figure 1: Disturbance definition

As the angular variable $\theta$ is one unknown of vector $\{Q\}$, the differential problem (7) is obviously non-linear.

\subsection{Solving problematic}

Solving equation (7) in the case of localized perturbations must be done carefully to ensure that all occurrences of the disturbance are represented with the same degree of accuracy. The choice proposed here is to solve the differential problem part by part, by looping over the number of occurrences of the disturbance and by breaking down each occurrence in three areas defined by the angles $\theta_{\mathrm{a}}, \theta_{\mathrm{b}}, \theta_{\mathrm{c}}, \theta_{\mathrm{d}}$ as shown Figure 1.b.

In each area defined in Fig. 1b, the expression of the disturbance is known as a function of the angular position $\theta$ and of the characteristics of the disturbance:

- area ab : $\mathrm{P}(\theta)=\mathrm{A}_{\mathrm{p}} * \sin \left(\frac{\pi}{\mathrm{L}_{\theta}} *\left(\theta-\theta_{\mathrm{a}}+\frac{\mathrm{L}_{\theta}}{2}\right)\right)$

- area bc : $\mathrm{P}(\theta)=0$

- area cd : $\mathrm{P}(\theta)=\mathrm{A}_{\mathrm{p}} * \sin \left(\frac{\pi}{\mathrm{L}_{\theta}} *\left(\theta-\theta_{\mathrm{c}}\right)\right)$

In each area, it is then possible to adjust the resolution parameters to ensure that the calculation is done with a sufficient number of discretization points. Let $\mathrm{n}_{\mathrm{ab}}, \mathrm{n}_{\mathrm{bc}}, \mathrm{n}_{\mathrm{cd}}$ be these numbers. This also ensures that for every occurrences of the disturbance, points of extreme amplitudes will be achieved and actually taken into account in the computation of the model dynamic response.

In the case of time resolution the problem is to determine, for each occurrence of the disturbance, the times $t_{a}, t_{b}, t_{c}, t_{d}$ where the characteristic angles $\theta_{\mathrm{a}}, \theta_{\mathrm{b}}, \theta_{\mathrm{c}}, \theta_{\mathrm{d}}$ are reached. If the system rotates at a constant macroscopic velocity $\omega_{\mathrm{o}}$ 
and if speed variations due to disturbance are very weak, these quantities can easily be estimated by :

$$
\mathrm{t}_{\mathrm{j}}=\frac{\theta_{\mathrm{j}}}{\omega_{\mathrm{o}}} \quad \mathrm{j}=\mathrm{a}, \mathrm{b}, \mathrm{c}, \mathrm{d}
$$

and the resolution of the differential system (6) presents no difficulty. As the objective of this paper is to focus on devices with large variations in macroscopic velocity, this case will not be discussed anymore.

In the more general case of macroscopic velocity variation, the above analysis can not be used. Detection of times $t_{a}$, $t_{b}, t_{c}, t_{d}$ must be done, but this involves algorithms using specific tools based for example on the technique of zero crossing.

\subsection{Solving using angular variable}

As the disturbances are angularly well defined and experimental results have demonstrated the interest of the angular sampling (or resampling) to analyze signals [7], the idea of expressing the equations of motion as a function of the variable $\theta$ which is the angular position of the defective element, rather than the time variable t, appears naturally.

In case of a rotating multi-d.o.f. system as defined above, the first step is to define the angular master d.o.f. $\theta$ driving the disturbance. Let $[\mathrm{T}]$ be the matrix operator that extracts from the state vector $\{\mathrm{Q}\}$ that d.o.f. $\theta$ and the associated angular velocity $\omega$.

$$
\left\{\begin{array}{c}
\theta \\
\omega
\end{array}\right\}=[\mathrm{T}]_{2 \times 2 \mathrm{n}} \cdot\{\mathrm{Q}\}_{2 \mathrm{n}}
$$

Classical time approaches consist in determining the temporal function $\phi(\mathrm{t})$ such that: $\theta=\phi(\mathrm{t})$.This function $\phi$ is invertible on the field of operation $\left[0 \mathrm{~T}_{\max }\right.$ if and only if:

$$
\forall \mathrm{t} \in\left[0 \mathrm{~T}_{\max }\right] \quad \frac{\mathrm{d} \phi(\mathrm{t})}{\mathrm{dt}}=\omega(\mathrm{t}) \neq 0
$$

i.e. if speed does not vanish during observation or simulation, which represents the vast majority of operating conditions of a rotating systems. Then one can use:

$$
\mathrm{t}=\phi^{-1}(\theta)=\psi(\theta)
$$

and performs the change of variable in the differential system (7).

For clarity let define:

$$
\begin{aligned}
& \{\tilde{\mathrm{Q}}(\theta)\}=\{\mathrm{Q}(\psi(\theta))\} \\
& \tilde{\omega}(\theta)=\omega(\psi(\theta))
\end{aligned}
$$

System (7) becomes:

$$
\begin{aligned}
& \{\dot{\mathrm{Q}}(\psi(\theta))\}=[\mathrm{A}(\theta)] \cdot\{\mathrm{Q}(\psi(\theta))\}+[\mathrm{B}]\left\{\begin{array}{c}
\{0\} \\
\left\{\mathrm{F}_{\text {ext }}\right\}+\Delta \mathrm{P}_{\mathrm{F}}(\theta) \cdot\left\{\mathrm{G}_{\mathrm{F}}\right\}
\end{array}\right\} \\
& \left\{\frac{\mathrm{d} \tilde{\mathrm{Q}}(\theta)}{\mathrm{d} \theta}\right\} \cdot \frac{\mathrm{d} \theta}{\mathrm{dt}}=[\mathrm{A}(\theta)] \cdot\{\tilde{\mathrm{Q}}(\theta)\}+[\mathrm{B}]\left\{\begin{array}{c}
\{0\} \\
\left\{\mathrm{F}_{\text {ext }}\right\}+\Delta \mathrm{P}_{\mathrm{F}}(\theta) \cdot\left\{\mathrm{G}_{\mathrm{F}}\right\}
\end{array}\right\}
\end{aligned}
$$

that leads to

$$
\left\{\begin{array}{l}
\left\{\frac{\mathrm{d} \tilde{\mathrm{Q}}(\theta)}{\mathrm{d} \theta}\right\}=\frac{1}{\tilde{\omega}(\theta)}\left([\mathrm{A}(\theta)] \cdot\{\tilde{\mathrm{Q}}(\theta)\}+[\mathrm{B}]\left\{\begin{array}{c}
\{0\} \\
\left\{\mathrm{F}_{\text {ext }}\right\}+\Delta \mathrm{P}_{\mathrm{F}}(\theta) \cdot\left\{\mathrm{G}_{\mathrm{F}}\right\}
\end{array}\right\}\right) \\
\frac{\mathrm{dt}}{\mathrm{d} \theta}=\frac{1}{\tilde{\omega}(\theta)} \quad \text { (b) }
\end{array}\right.
$$


The time differential problem has become an angular differential problem. Matrices $[\mathrm{A}]$ and $[\mathrm{B}]$ are the same as in time modeling. It must be noticed that the matrix system (13.a) has a trivial line which could be deleted (14).

$$
\frac{\mathrm{d} \theta}{\mathrm{d} \theta}=1
$$

Then the system will be formed of $2 \mathrm{n}$ differential equations of order 1 .

\section{Comparative studies of time and angular methods of resolution for a one d.o.f. system}

\subsection{System definition}

We consider in this part a rotating system modeled by one rotating degree of freedom $\theta$, and a perturbation leading to an external torque variation $\Delta \mathrm{P}_{\mathrm{T}}(\theta)$. Let $\mathrm{I}\left(0.012 \mathrm{Kg} . \mathrm{m}^{4}\right)$ be the inertia of this system and $\mathbf{c}_{\mathrm{T}}(0.0057 \mathrm{~N} . \mathrm{m} . \mathrm{s} / \mathrm{rad})$ the equivalent viscous damping. This system is also submitted to a motor torque $\mathrm{T}_{\mathrm{M}}$ that can be time-dependent but without localized phenomenon. Dynamic matricial equation (6) becomes a scalar one:

$$
\text { I. } \ddot{\theta}+\mathrm{c}_{\mathrm{T}} \dot{\theta}=\mathrm{T}_{\mathrm{M}}(\mathrm{t})+\Delta \mathrm{P}_{\mathrm{T}}(\theta)
$$

For time resolution approach, this system becomes:

$$
\left\{\begin{array}{l}
\frac{\mathrm{d} \theta}{\mathrm{dt}}=\Omega \\
\frac{\mathrm{d} \Omega}{\mathrm{dt}}=\frac{1}{\mathrm{I}}\left(-\mathrm{c}_{\mathrm{T}} \cdot \Omega+\mathrm{T}_{\mathrm{M}}(\mathrm{t})+\Delta \mathrm{P}_{\mathrm{T}}(\theta)\right)
\end{array}\right.
$$

And for angular resolution approach, it becomes

$$
\left\{\begin{array}{l}
\frac{\mathrm{d} \tilde{\mathrm{t}}}{\mathrm{d} \theta}=\frac{1}{\tilde{\Omega}} \\
\frac{\mathrm{d} \tilde{\Omega}}{\mathrm{d} \theta}=\frac{1}{\tilde{\Omega}} \cdot \frac{1}{\mathrm{I}}\left(-\mathrm{c}_{\mathrm{T}} \cdot \tilde{\Omega}+\mathrm{T}_{\mathrm{M}}(\mathrm{t})+\mathrm{P}(\theta)\right)
\end{array}\right.
$$

\subsection{Step response}

To verify the validity of angular equations the step responses obtained for time and angular resolution approaches are compared. The system is supposed to be in a steady state ( $\left.\mathrm{T}_{\mathrm{M} 0}=0.74 \mathrm{~N} \cdot \mathrm{m}, \Omega=129.8 \mathrm{rad} / \mathrm{s}\right)$ and at the initial time of the computation the motor torque increases to $2 \mathrm{~T}_{\mathrm{M} 0}$. For both approaches, the minimum number of integration points is set at one million. This number is intentionally high in order to better estimate the influence of the approach on the CPU time. In both case, solving is performed using Matlab ODE113 function. To compare the CPU time of both approaches, the integration range must be the same. This range is set at $10 \mathrm{~s}$ for the time resolution; the results of this first simulation are used to determine the angular integration range (corresponding final angle to reach). The evolution curves of the angular velocity are given for both approaches in the following figure.
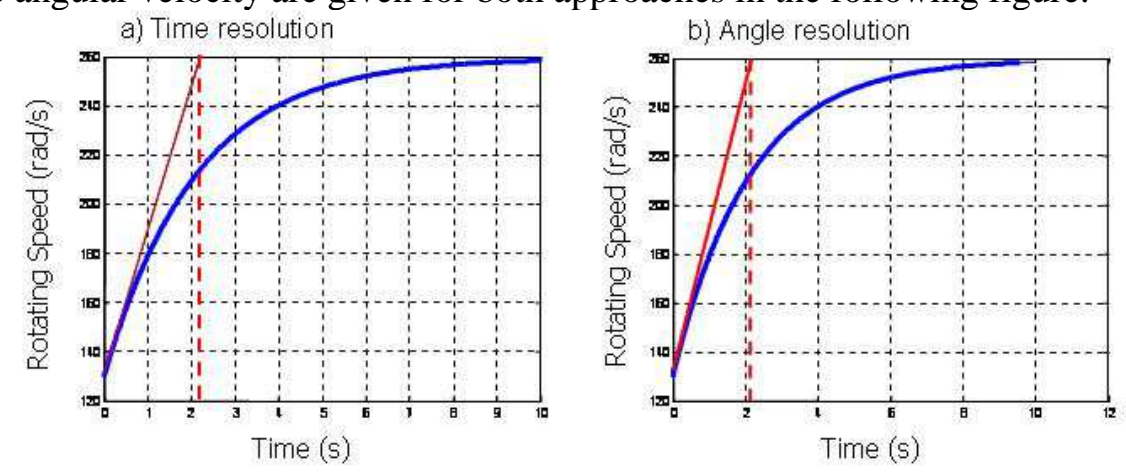

Figure 2: 1 D.o.f. system comparison of step responses obtained for time resolution (a) and angle resolution (b) 
It appears that the results are identical and the values in steady and initial slope are conforming to the theory:

$$
\begin{aligned}
& \Omega_{\infty}=\frac{\mathrm{C}_{\mathrm{M}}}{\mathrm{c}_{\mathrm{T}}}=260 \mathrm{rad} / \mathrm{s} \\
& \tau=\frac{\mathrm{I}}{\mathrm{c}_{\mathrm{T}}}=2.1 \mathrm{~s}
\end{aligned}
$$

These identical results validate the setting equation of angular approach.

The integration times are almost identical: 452 s for time resolution and 453s for angle one.

\subsection{Revving of the engine and angular disturbance}

In this section, we consider the case of a revving corresponding to a linear increase in engine torque:

$$
\mathrm{T}_{\mathrm{M}}(\mathrm{t})=(0.74+0.37 \mathrm{t}) \quad \mathrm{N} . \mathrm{m}
$$

combined with the effects of a perturbation whose angular parameters are gathered in the following table:

\begin{tabular}{ccc}
\hline $\boldsymbol{\theta} \mathbf{o}(\mathbf{r a d})$ & $\mathbf{L}_{\boldsymbol{\theta}}(\mathbf{d e g})$ & $\mathbf{A p}(\mathbf{N} . \mathbf{m})$ \\
\hline $2 . \pi / 5.7$ & 0.5 & 0.0074 \\
\hline
\end{tabular}

Table 1: Torque perturbation parameters

The resolution is about 570 occurrences of the disturbance; the numbers of minimum calculation points in the different areas are set at $\mathrm{n}_{\mathrm{ab}}=\mathrm{n}_{\mathrm{cd}}=20$ and $\mathrm{n}_{\mathrm{bc}}=80$. Initial speed is set to:

$$
\omega_{0}=\frac{\mathrm{T}_{\mathrm{M}}(0)}{\mathrm{c}_{\mathrm{T}}}=128.8 \mathrm{rad} / \mathrm{s}
$$

\begin{tabular}{|c|c|c|c|c|c|c|c|}
\hline & Ode113 & Ode45 & Ode23 & Ode23s & Ode23t & Ode23tb & Ode15s \\
\hline \multicolumn{8}{|c|}{ Time Resolution } \\
\hline Times (s) & 37.86 & 86.86 & 42.91 & 70.26 & 37.19 & 43.56 & 44.44 \\
\hline $\begin{array}{l}\text { Number of } \\
\text { integrating points }\end{array}$ & 57002 & 228005 & 57002 & 57002 & 57002 & 57002 & 57002 \\
\hline \multicolumn{8}{|c|}{ Angle Resolution } \\
\hline Times (s) & 28.85 & 86.4 & 34.91 & 67.38 & 28.01 & 36.84 & 41.55 \\
\hline $\begin{array}{l}\text { Number of } \\
\text { integrating points }\end{array}$ & 68401 & 273601 & 68401 & 68401 & 68401 & 68401 & 68401 \\
\hline
\end{tabular}

The following table shows, for the angle and time resolutions and different solvers available in the basic module of Matlab, the time resolution and the effective number of computation points.

Table 2: Comparison of Time and Angle resolution approaches

It appears that whatever the method of resolution used, angle resolution approach is faster than the time one. Also, the number of effective calculation points is 1.2 times larger with angular approach that leads to a smaller resolution step.

The resolution method ODE45 (Runge-Kutta explicit) is distinguished from others by a number of calculation points four times larger and by comparable computing times for both approaches (86s) but significantly higher than with other solvers.

ODE113 methods (variable order Adams-Bashforth-Moulton PECE) and ODE23t (implementation of the trapezoidal rule using a "free" interpolant) are the fastest for both approaches.

\subsection{Conclusion}

In the case of a 1 d.o.f system, introduction of a periodic and angularly located disturbance, using the angle approach appears to be more efficient than the classical time method coupled to a method of zero-crossing. Indeed resolution times are shorter, the number of calculation points is larger and more regular, and parameter settings are easiest to choose. What's more, there are no special precautions to ensure the correct locations of integration points. The description of the angular periodic disturbance is also easiest to be set in the angular domain, for gears as for bearings. 
Moreover, if the object of the study is the analysis of behavior under non-stationary conditions without disturbance angular approach can also be considered. The computation time will be identical to those of a conventional temporal approach, but the accuracy of the angular pitch will be better controlled and will be independent of the macroscopic velocity of the mechanical system.

\section{Application to the modeling of a real device with bearing defects}

\subsection{Brief recalls about angular sampling and Instantaneous Angular Speed measurement}

For rotating systems, the principle of angular sampling is not new and different approaches are possible [7]. One revolution shaft is chosen as reference and measured signals are sampled with a constant angle step rather than with a constant time step. The usual techniques of signal processing may be applied, particularly the transformation in the frequency domain using the Fourier transform. The spectra are then expressed in cyclic frequency ${ }^{l}$ whose unit is a number of events per revolution. In our experimental tests and simulations, this sampling is made with the help of an optical encoder which resolution is R. This approach allows the measurement of Instantaneous Angular Speed by elapse time method that consists in counting the number $\mathrm{n}_{\mathrm{c}}$ of a high frequency clock ticks between two successive pulses of the encoder signal. Let $\mathrm{f}_{\mathrm{c}}$ be the clock frequency. This allows estimating the average speed $\bar{\omega}_{\mathrm{i}}$ for each angular step $\Delta \theta_{\mathrm{i}}$ by:

$$
\bar{\omega}_{\mathrm{i}}=\frac{\Delta \theta}{\Delta \mathrm{t}}=\frac{2 \pi}{\mathrm{R}} \cdot \frac{1}{\mathrm{n}_{\mathrm{c}}} \mathrm{f}_{\mathrm{c}}
$$

These methods of measurement and analysis have been applied to an automotive gearbox (fig3a) [9]. They show that despite macroscopic velocity variations, analysis in angular frequency domain allows detecting characteristic angular frequencies corresponding to the presence of mechanical defects (fig 3b). These findings are confirmed by measurements on other devices [9]. In the context of bearing monitoring one original result of these approaches is that the presence of a defect on a bearing ring leads to measurable changes in rotating speed. Mechanically this means that the presence of bearing defects has tangential effects and not only radial ones as this is usually considered [10]. This opens up new ways of research for monitoring and maintenance of rotating systems.

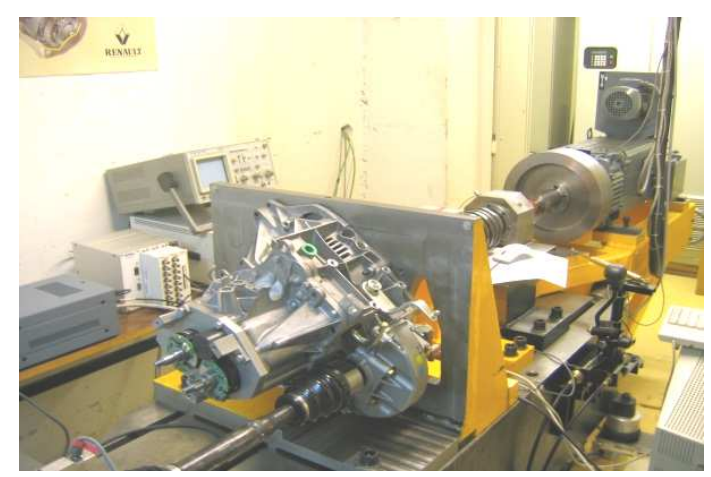

(a)

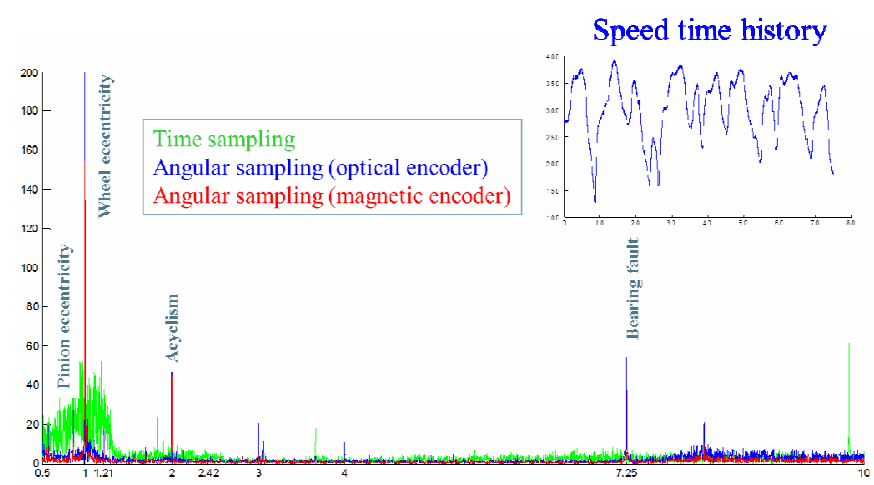

(b)

Figure 3: (a) Gearbox test bench (b) Example of spectral angular analyses for non-stationary conditions

\subsection{Specific test bench}

In order to understand the relationship between the presence of a defect in bearing and changes in measured Instantaneous Angular Speed, a specific test bench has been developed (Fig. 4a). It consists of a shaft supported by two tapered roller bearings that may have defects in their outer ring (fig $4 \mathrm{~b}$ ). These defects correspond to a theoretical characteristic angular frequency of 7.26 events per revolution. This bearing is also used on the automotive gearbox test bench.

\footnotetext{
${ }^{1}$ To the authors' knowledge there is no dedicated name for this quantity. This must be also related to recent developments in signal processing in the field of cyclostationarity.
} 
An original device formed of a spherical bearing and two springs allows applying radial loads adjustable and independently of rotation speed. An axial preload can also be applied in the form of an imposed displacement of one bearing outer ring.

A high resolution optical encoder $(R=5000$ pulses per revolution), not shown in Figure 4a, coupled to an acquisition device with a clock frequency $\mathrm{f}_{\mathrm{c}}=80 \mathrm{MHz}$ ensures the angular sampling and measurement of the Instantaneous Angular Speed by the counting method.

One interest of this bench is, for a given bearing fault, to test the effects of operating parameters (load, macroscopic velocity) on the rotating speed variations and additionally to compare for a given operating condition, the influence of the fault (width, surface, ...) in the same rotational speed condition.

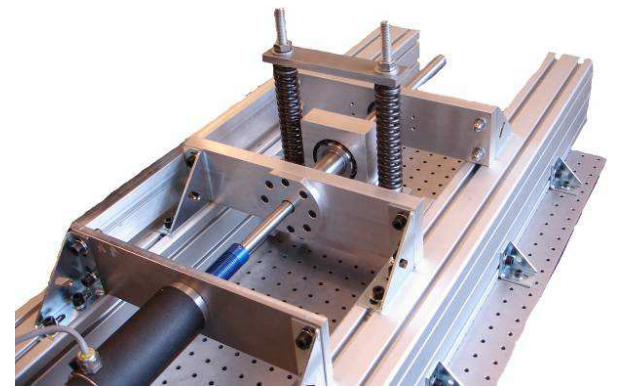

(a)

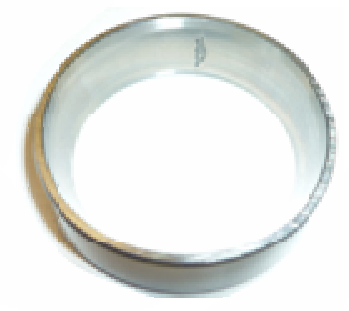

(b)

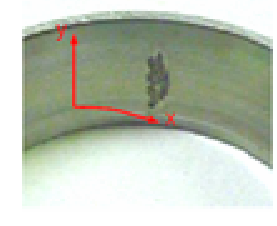

Figure4: (a) Specific test bench (b) Example of fault on bearing outer ring

\subsection{Description of a torsional model of the specific test bench}

As a complement to these experimental approaches, a numerical model of the bench has been developed. Given that the analyzed signal is the rotating speed and that the experimental bench has no coupling between the effects of torsion, bending and tension-compression, the model considered in this first approach is a purely torsional one.

The steel shaft of length $L_{a}$, diameter $d$, Coulomb modulus $G$, density $\rho$ is discretized in $n_{\text {elt }}=10$ elements of equal length $\mathrm{L}=\mathrm{L}_{\mathrm{a}} / \mathrm{n}_{\text {elt }}$, the section changes are not considered. Each element is characterized by its following elementary matrices of mass, stiffness and damping:

$$
\begin{gathered}
{\left[\mathrm{M}_{\mathrm{e}}\right]=\left[\begin{array}{cc}
\mathrm{I} & \frac{1}{2} \mathrm{I} \\
\frac{1}{2} \mathrm{I} & \mathrm{I}
\end{array}\right] \text { with } \mathrm{I}=\frac{\pi \cdot \mathrm{d}^{4}}{32} \cdot \frac{1}{3} \cdot \rho \cdot \mathrm{L}} \\
{[\mathrm{Ke}]=\left[\begin{array}{cc}
\mathrm{k}_{\mathrm{e}} & -\mathrm{k}_{\mathrm{e}} \\
-\mathrm{k}_{\mathrm{e}} & \mathrm{k}_{\mathrm{e}}
\end{array}\right] \text { with } \mathrm{k}_{\mathrm{e}}=\frac{\mathrm{G}}{\mathrm{L}} \cdot \frac{\pi \cdot \mathrm{d}^{4}}{32}} \\
{\left[\mathrm{C}_{\mathrm{se}}\right]=\left[\begin{array}{cc}
\mathrm{c}_{\mathrm{s}} & -\mathrm{c}_{\mathrm{s}} \\
-\mathrm{c}_{\mathrm{s}} & \mathrm{c}_{\mathrm{s}}
\end{array}\right]}
\end{gathered}
$$

coefficient $\mathrm{c}_{\mathrm{s}}$ will be defined later.

The assembly of the 10 elementary matrices leads to the definition of matrices of mass [M], structural damping [Cs], stiffness [K] of dimension $11 \times 11$.

Equivalent viscous dampers $c_{\mathrm{ei}}$ representing the external damping due to the bearings are also introduced between d.o.f. of the shaft and the housing. The values $c_{e i}$ of these dampers will be determined later. Let $\left[\mathrm{C}_{\mathrm{e}}\right]$ be the damping matrix associated with these dampers.

For studies presented in this paper, the effects of bearing fault are considered in the form of an external force, here a torque $\mathrm{T}_{\mathrm{pA}}$, applied at the d.o.f. associated to the defective bearing (bearing $\mathrm{A}$ ). A schematic representation of the model is given in figure 5 and table 3 summarizes the main values of the modeling.

\begin{tabular}{llll}
\hline $\mathrm{L}_{\mathrm{a}}(\mathrm{mm})$ & $\mathrm{d}(\mathrm{mm})$ & $\mathrm{G}(\mathrm{MPa})$ & $\rho\left(\mathrm{Kg} \cdot \mathrm{m}^{3}\right)$ \\
\hline 53 & 25 & 83333 & 7500
\end{tabular}

Table 3: Modeling values 


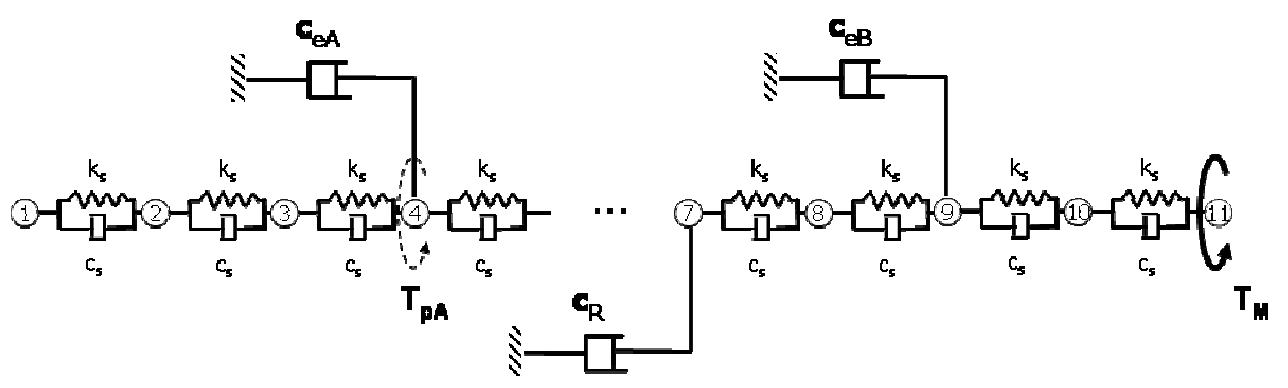

Figure 5: Schematic model

The value of structural damping coefficient $\mathrm{c}_{\mathrm{s}}$ is determined by considering that for steel it is equal to $0.66 \%$ of critical damping. This critical damping corresponds to the value $\mathrm{c}_{\mathrm{sc}}$ for which the solutions of equation (22) are not harmonic, that is to say when the nonzero eigenvalues of the matrix [A] are no longer complex conjugated.

$$
\{\dot{\mathrm{X}}(\mathrm{t})\}=[\mathrm{A}] .\{\mathrm{X}(\mathrm{t})\}
$$

In the case where the external dampers $c_{\mathrm{ei}}$ are zero, it is possible to calculate the eigenvalues of the matrix [A] defined in equation (7), for different values of $\mathrm{c}_{\mathrm{s}}$. This leads to a value of critical damping:

$$
\mathrm{c}_{\mathrm{sc}}=0.55 \mathrm{Nms} / \mathrm{rad} \text {. }
$$

One takes a structural damping value of

$$
\mathrm{c}_{\mathrm{s}}=0.0036 \mathrm{Nms} / \mathrm{rad} \text {. }
$$

For tapered roller bearings and spherical bearing and for a given rotational speed $\mathrm{N}$ and a given load, the total friction torque $\mathrm{T}_{\mathrm{f}}$ can be estimated using the calculation sheet available on SKF website ${ }^{2}$. It is then possible to estimate an equivalent viscous damping value. Application will be performed in section 5.3

The simulation parameters are the motor torque $\mathrm{T}_{\mathrm{M}}$ which may be constant or variable versus time and the characteristics of the disturbances: $\theta_{0}, L_{\theta}, A_{p}$.

Otherwise, in order to compare the experimental and numerical results, the measuring principle of the I.A.S. must be simulated. This is needed to reproduce method described in section 4.1 to digital signals available at the end of calculations, namely the time $\{\mathrm{T}\}$ and the angular position of each d.o.f. The simulation of the acquisition is done as follows:

- Definition of encoder d.o.f. which corresponds to the position where the angular position measurement is carried out. For the model considered in this paper, the encoder will be positioned at the shaft end; the encoder d.o.f will be the d.o.f. \#1. Note that the choice of this d.o.f. is completely independent of the d.o.f. driving the perturbation in the steps of the differential problem resolution. Let $\left\{\theta_{c}\right\}$ be the vector of computed angular positions of this d.o.f. They are not equally distributed because the resolution of the differential system is not done with a constant angular step.

- Definition of angular positions corresponding to the angular sampling positions:

$$
\left\{\theta_{\mathrm{e}}\right\}=\left\{\begin{array}{llll}
0 & \Delta \theta & 2 . \Delta \theta & \cdots
\end{array}\right\} \quad \text { with } \quad \Delta \theta=\frac{2 \pi}{\mathrm{R}}
$$

- Estimation of elapsed time $\left\{\mathrm{T}_{\mathrm{e}}\right\}$ when the angular positions $\left\{\theta_{\mathrm{e}}\right\}$ are reached, this is performed with linear interpolation from the values of $\{\mathrm{T}\}$ known for angular positions $\left\{\theta_{\mathrm{c}}\right\}$

- Calculation of time "measured" by the counting method :

$$
\mathrm{T}_{\mathrm{mi}}=\left\lceil\mathrm{T}_{\mathrm{ei}} \mathrm{f}_{\mathrm{h}}\right\rceil \cdot \frac{1}{\mathrm{f}_{\mathrm{h}}} \text { where }\lceil\mathrm{x}\rceil \text { is the function that rounds } \mathrm{x} \text { to the next integer }
$$

- Calculation of the time gaps $\tau_{\mathrm{m}}$ between two sampling angular positions :

2

2 http://www.skf.com/skf/productcatalogue/calculationsFilter?lang=en\&newlink=\&prodid=\&action=Calc5 


$$
\tau_{\mathrm{m}}(\mathrm{i} \Delta \theta)=\tau_{\mathrm{m}}\left(\theta_{\mathrm{ei}}\right)=\tau_{\mathrm{mi}}=\mathrm{T}_{\mathrm{m}}\left(\theta_{\mathrm{ei}}\right)-\mathrm{T}_{\mathrm{m}}\left(\theta_{\mathrm{ei}-1}\right)
$$

- Calculation of the average speed on each angular interval $\left[\theta_{\mathrm{i}-1} \theta_{\mathrm{i}}\right]$ :

$$
\omega_{\mathrm{mi}}=\frac{2 \pi}{\mathrm{R} \cdot \tau_{\mathrm{mi}}}
$$

The sets of values and $\left\{\tau_{\mathrm{m}}\right\}$ and $\left\{\omega_{\mathrm{m}}\right\}$ are then comparable to values obtained from experimental measurements.

\section{Validation of the approach and analyzes}

\subsection{Test bench accuracy}

The thrust of this work is to detect the presence of defects on the bearing rings through the analysis of the Instantaneous Angular Speed signal in the case of systems operating under non-stationary conditions. To confirm the validity of this approach measurements are carried out on the bench previously described in the case of a healthy bearing and in the case of a bearing with a defect on the outer ring as shown in figure 6 .

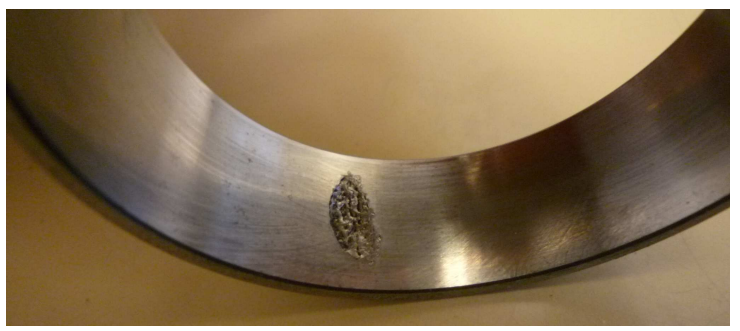

Figure 6: Defect on bearing outer-ring

In both cases, the measurements are performed during a ramp-up and analyzed using cyclic frequency diagrams. Note that the increase in speed control is done manually and cannot be exactly reproduced as shown in Figure 7.
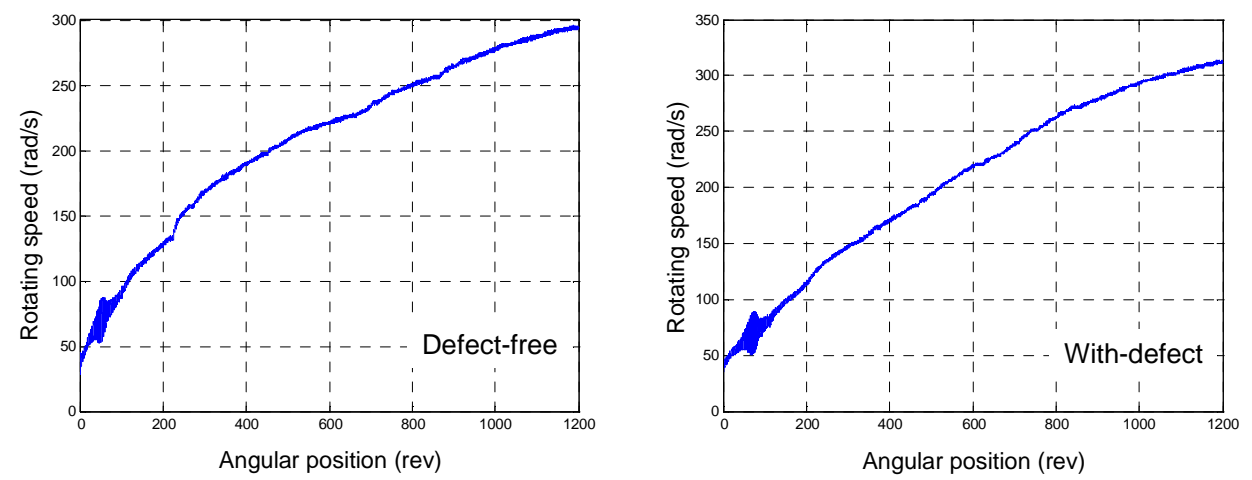

Fig 7: Rotating speed ramp-up

This signal is analyzed using angular cyclic frequency spectrograms ${ }^{3}$ which are an extension of time-frequency analysis to angular approach. Results are presented in Figure 8. The presence of the defect on the outer ring is clearly visible in the form of horizontal lines corresponding to the characteristic cyclic frequency $(7.3 \mathrm{ev} / \mathrm{rev})$ and its harmonics. The exponential curve corresponds to a resonance of the structure. The combination of the spectrograms and velocity ramp-up values are used to identify its natural frequency around $480 \mathrm{~Hz}$. This eigenmode has not yet been specifically identified on the test bench. It can correspond to the first bending mode of the drive shaft or to a torsion mode with low frequency due to the presence of a flexible coupling between the motor and the shaft which torsional rigidity is not known.

These results confirm the possibility of detecting bearing defects by analyzing the Instantaneous Angular Speed signal in the angular space even if the device is operating under non-stationary.

${ }^{3}$ The use of this term may be considered abusive, but the authors do not know better suited. 

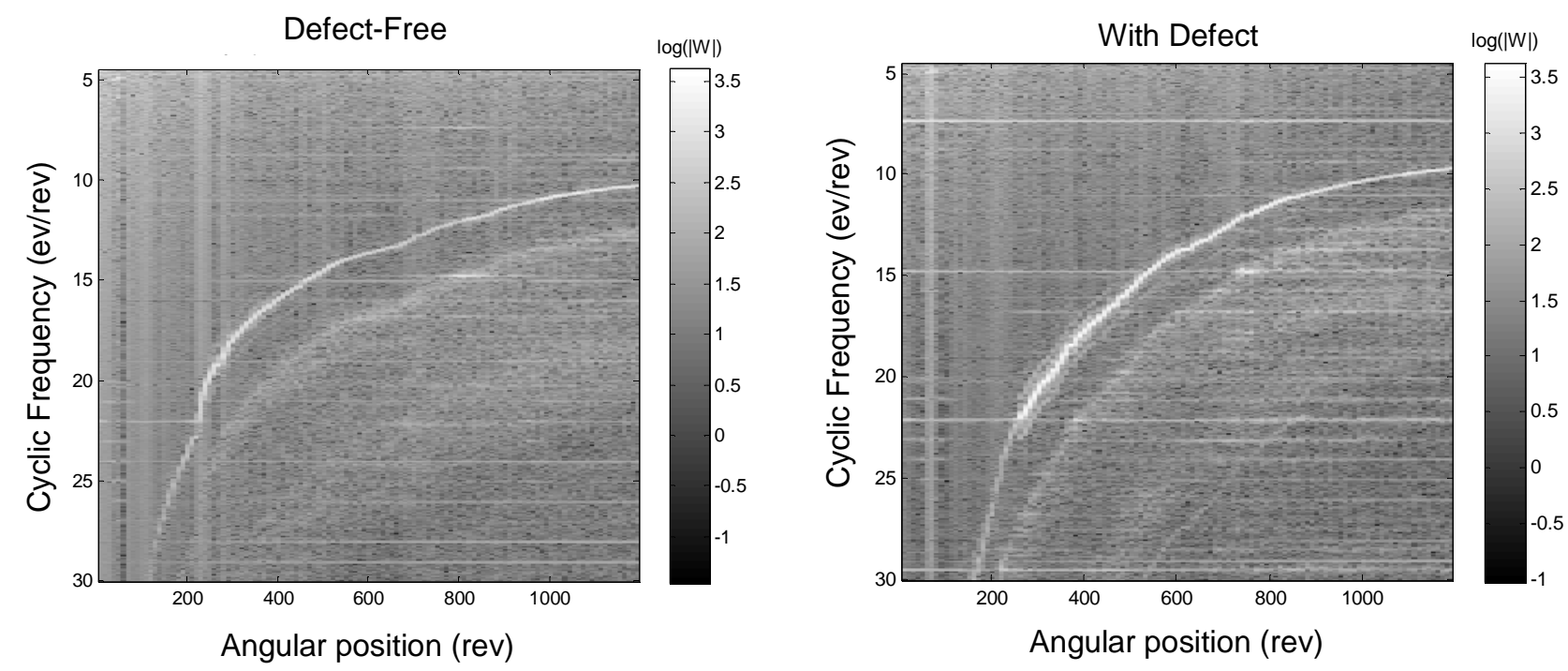

Figure 8: Angular - Cyclic Frequency spectrograms of Instantaneous Angular Speed.

\subsection{Model accuracy}

The objective of this section focuses on the verification of the assumption that the presence of a defect on a bearing ring leads to a localized and angular periodic disturbance torque is realistic. This is done by using the experimental results obtained under steady conditions for the previous fault. A first set of measurements was carried out for a radial load of $3100 \mathrm{~N}$, an axial bearing preload of $0.3 \mathrm{~mm}$, a control voltage of the motor of $4.55 \mathrm{~V}$ and over 200 shaft revolutions which leads to a frequency resolution of 0.005 events per revolution in the cyclic frequency domain.

Figure 9a shows the speed variations. Speed has macroscopic variations around $1125 \mathrm{rpm}$ with cyclic frequency of 1 even/rev. The origin of this variation is not yet identified. We consider thereafter that it is generated by the electrical engine and its electronics. Figure $9 \mathrm{~b}$ shows the corresponding angular spectra, the macroscopic speed variation leads to the emergence of lines of cyclic frequencies at 1 and 2 events per revolution. Effects of disturbance due to the bearing fault can be found in Figure 9c with its fundamental frequency of 7.3 events per revolution and its harmonics.
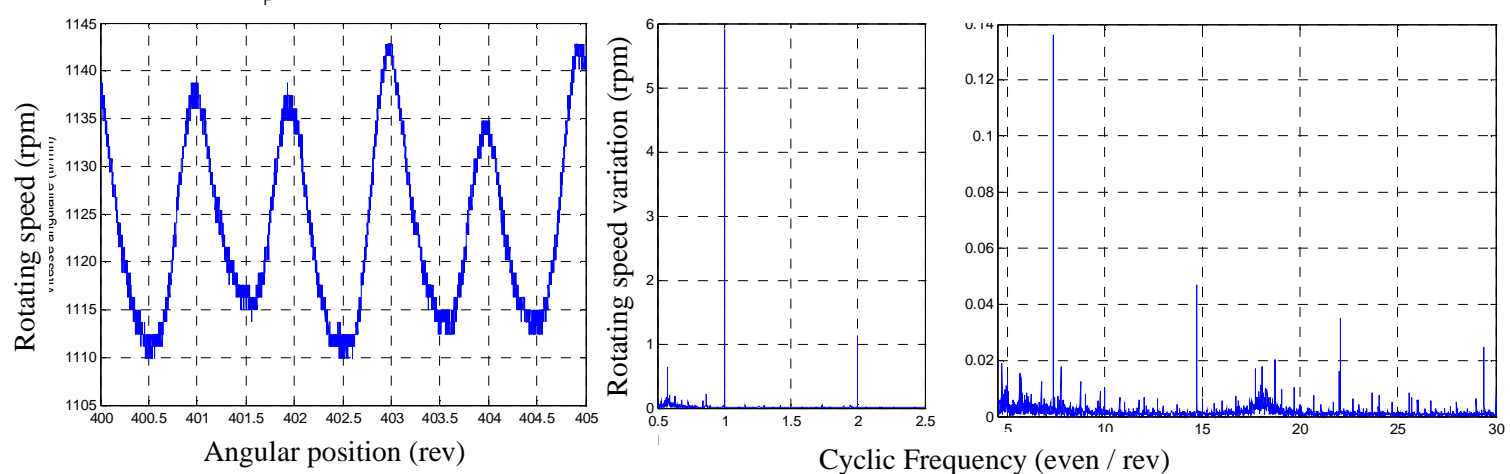

Figure 9: Experimental rotating speed variations

We now verify that the proposed numerical model leads to similar results. Numerical simulations are performed assuming that the engine torque is of the following form:

$$
\mathrm{T}_{\mathrm{M}}=\mathrm{T}_{0}+\mathrm{A}_{\mathrm{M}} \cdot \sin \left(\mu_{\mathrm{M}} \cdot \theta\right) \text {. }
$$

Table 4 summarizes the characteristics of modeling and resolution used.

\begin{tabular}{|c|c|c|c|c|c|c|c|c|c|c|}
\hline \multicolumn{2}{|c|}{ Bearing dampers } & \multicolumn{3}{|c|}{ Driving Torque } & \multicolumn{3}{|c|}{ Perturbation } & \multicolumn{3}{|c|}{ Resolution Parameters } \\
\hline $\begin{array}{c}\mathrm{c}_{\mathrm{eA}}=\mathrm{CeB} \\
(\mathrm{N} . \mathrm{m} . \mathrm{s} / \mathrm{rad})\end{array}$ & $\begin{array}{c}\mathrm{C}_{\mathrm{eR}} \\
\text { (N.m.s/rad) }\end{array}$ & $\begin{array}{c}\text { To } \\
\text { (N.m) }\end{array}$ & $\begin{array}{c}\mathrm{A}_{\mathrm{M}} \\
\text { (N.m) }\end{array}$ & $\begin{array}{c}\mu_{\mathrm{M}} \\
(\mathrm{ev} / \mathrm{tr})\end{array}$ & $\begin{array}{c}\mu_{\theta} \\
(\mathrm{ev} / \mathrm{tr})\end{array}$ & $\begin{array}{c}\mathrm{L}_{\theta} \\
(\mathrm{deg})\end{array}$ & $\begin{array}{c}\mathrm{A}_{\mathrm{p}} \\
(\mathrm{N} . \mathrm{m})\end{array}$ & $\begin{array}{c}\mathrm{Nb} \\
\text { occurrences }\end{array}$ & $\mathrm{n}_{\mathrm{ab}}=\mathrm{n}_{\mathrm{cd}}$ & $\mathrm{n}_{\mathrm{bc}}$ \\
\hline $2.810^{-3}$ & $710^{-4}$ & 0.74 & 0.02 & 1 & 7.3 & 10 & $1.510^{-4}$ & 500 & 10 & 40 \\
\hline
\end{tabular}

Table 4: Characteristics of modeling and resolution 
Computed Instantaneous Angular Speed and its angular spectral amplitude are given in figure 10. The very good agreement between experimental and numerical results allows validating the accuracy of the proposed model and thereby confirming the existence of an interaction between a bearing defect and the Instantaneous Angular Speed of the device.

The digital approach also allows estimating the amplitude of the disturbing torque generated by the presence of a defect of the bearing that leads to similar results than experimental ones. In this case, a disturbance torque with the shape of a half sine of amplitude $1.510^{-4} \mathrm{Nm}$ produces results in Instantaneous Angular Speed comparable to those measured experimentally. This quantity must be compared to other torques present in the device in particular frictionnal moment in the bearings which can be estimated using SKF online tools. For bearings and operating conditions considered in this section, this friction torque is estimated at $0.33 \mathrm{Nm}$ is 2200 times higher than the disturbing torque previously estimated. This makes plausible the assumption that the presence of a defect on bearing ring leads to the emergence of a torque with a very small amplitude probably reflecting changes in phenomena occurring in the contact zone between the rolling elements and the raceways. Moreover these results confirm the accuracy and the sensitivity of the experimental results and analyzes done with the Instantaneous Angular Speed signal and angular sampling approach.
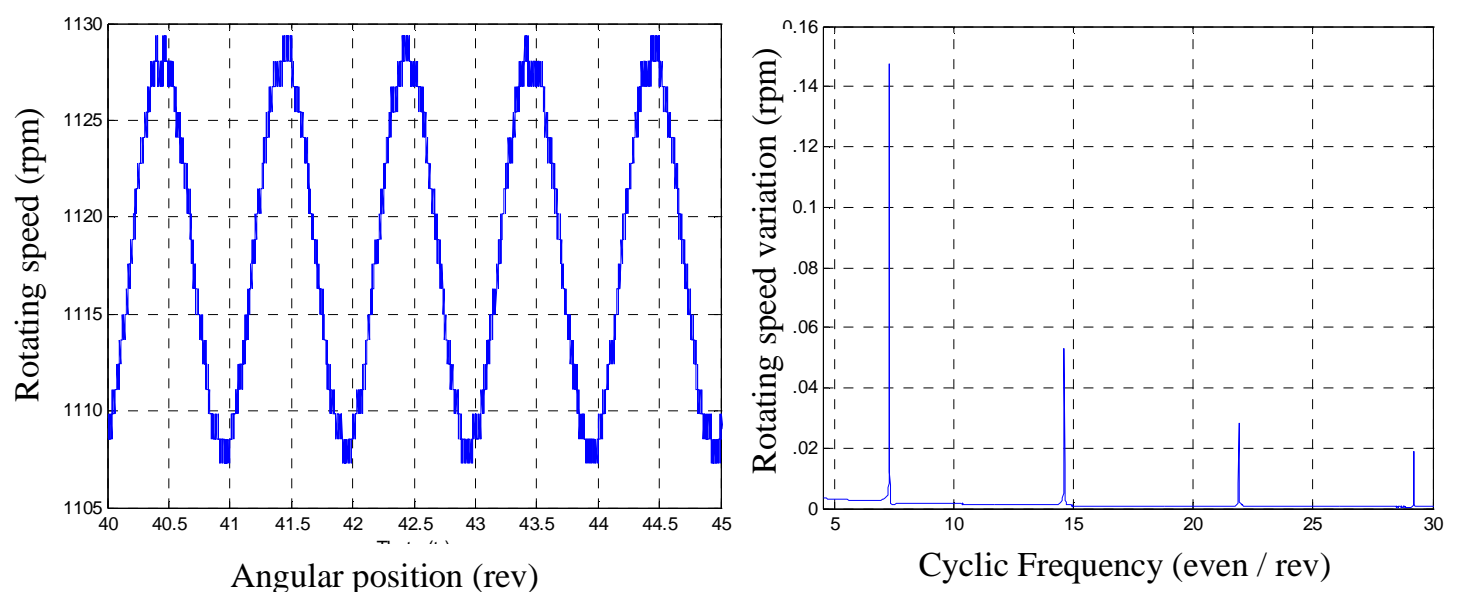

Figure 10: Numerical Instantaneous Angular Speed variations

\section{Conclusion and perspectives}

The works presented in this paper is based on previous results which have shown the interest of the angular approach for sampling and analyzing vibration signals and the Instantaneous Angular Speed signal for monitoring rotating machines. These studies have shown that the presence of a defect in bearings is detectable by simple spectral analysis of the Instantaneous Angular Speed if it is sampled in angle domain. These facts being established, the measurements performed on complex devices do not allow to clearly identify the relationships between mechanical origins and effects of faults on the global behavior of the machine. To gain a better understanding of these phenomena an original approach introducing a localized and angularly periodic defect in a numerical model is proposed in this paper. Doubts about the resolution time and the interest of such approach are removed: it is easier to introduce the periodic perturbation description with differential angular formulation than with time formulation and computation times are shorter. It remains to adjust the optimal number of points $n_{a b}, n_{b c}$ and $n_{c d}$ to ensure accurate results and acceptable computation time. In the same time, an experimental test bench that allows separating the rotation speed and load effects was developed and presented. The comparison of the first experimental and numerical results allows the validation of the proposed approach. These results have also given a first estimation of the torque variation induced by the presence of a defect on the outer race of a tapered bearing. These results are the first steps towards the establishment of tools for monitoring the bearing defect evolution in an alternative way of classical vibration analysis.

All of these results are very encouraging for the continuation of this work. From this perspective, a measurement campaign is underway for various operating configurations (speed and load) and various defects on the bearing outer race. Associated with existing numerical models, the analysis of these trials will help to carry out investigations on "physical" sources (variations in effort, damping ...) of the disturbance leading to changes in the measured 
Instantaneous Angular Speed. It will also allow studying the coupling between the modes of the structure, in particular twist modes and responses to angularly periodic perturbations. It will also assess the influence of the optimal position of the speed sensor.

From a numerical point of view it is intended, among other things, to investigate the influence of the shape of the disturbance on the Instantaneous Angular Speed. It is also intended to introduce this disturbance in the form of variation of damping and/or stiffness to determine the right modeling leading to results closest to experimental results. Extension to more complete models incorporating all of the rotating shaft d.o.f. especially flexion ones will be considered thereafter. From a methodological point of view there is no problem in principle to reach this extension: the approach presented in section 2.3 remains valid, but we will wonder about how to introduce the bearing stiffness in such angular models.

It is also projected to introduce several disturbances with different cyclic frequencies in more complex systems like gearboxes for validating sources identification related to kinematics.

\section{References}

1. Y. JIANGUO, P. LIJUN, W. ZHIHUA, Z. YICHEN and Y. XINPING, Fault detection in a diesel engine by analysing the instantaneous angular speed, Mechanical Systems and Signal Processing, vol. 15, no 3, p. 549 - 564, (2001).

2. L. YUHUA, F. GU, G. HARRIS, A. BALL, N. BENETT, and K. TRAVIS, The measurement of instantaneous angular speed, Mechanical Systems and Signal Processing 19(4), 786-805, (2005)

3. D. RÉMOND and J. MAHFOUDH, From Transmission Error measurements to angular sampling in rotating machines with discrete geometry. Shock and Vibration, 12(2):149-161, (2005).

4. S. YU, X. ZHANG, A data processing method for determining instantaneous angular speed and acceleration of crankshaft in an aircraft engine-propeller system using a magnetic encoder, Mechanical Systems and Signal Processing, vol. 24, no 4, p. 1032 - 1048, (2010).

5. F. GU, I. YESILYURT, L. YUHUA, G. HARRIS and A. BALL, An investigation of the effects of measurement noise in the use of instantaneous angular speed for machine diagnosis, Mechanical Systems and Signal Processing, vol. 20, no 6, p. 1444-1460, (2006).

6. L. RENAUDIN, F. BONNARDOT, O. MUSY, J.B. DORAY, and D. RÉMOND, Natural roller bearing fault detection by angular measurement of true instantaneous angular speed, Mechanical Systems and Signal Processing 24(7), 1998-2011, (2010).

7. H. ANDRÉ, J. ANTONI, Z. DAHER and D. RÉMOND, Comparison between angular sampling and angular resampling methods applied on the vibration monitoring of a gear meshing in non-stationary conditions, in 'Proceedings of the International Conference on Noise and Vibration Engineering', Leuven, Belgium, September 20-22, (2010).

8. F. BONNARDOT, M. EL BADAOUI, R. RANDALL, J. DANIERE, F. GUILLET, Use of the acceleration of a gearbox in order to perform angular resampling (with limited speed fluctuation), Mechanical Systems and Signal Processing, vol. 19, p. 766-785, (2005).

9. H. ANDRÉ, A. BOURDON and D. RÉMOND, On the use of the Instantaneous Angular Speed measurement in non-stationary mechanism monitoring, in 'Proceedings of the ASME 2011 International Design Engineering Technical Conferences', paper DETC2011/MECH-47470, Washington DC, USA, August 28-31, (2011).

10. A. BOURDON, H. ANDRÉ AND D. RÉMOND, A New way of writing motion equation in rotating machines by translation into the angular domain, in 'Proceedings of the 8th IFToMM International Conference on Rotordynamics, KIST, Seoul, Korea, September 12-15, (2010). 